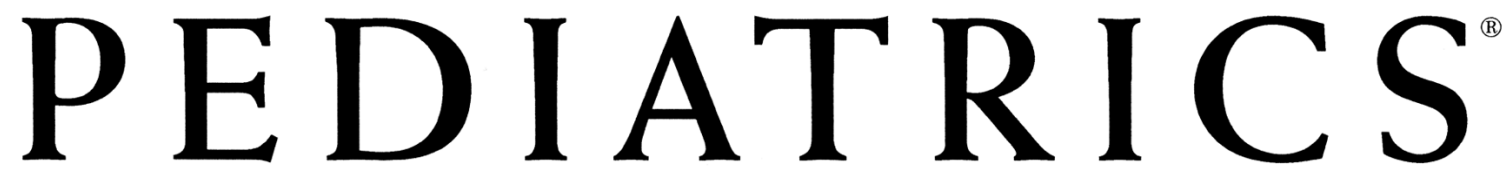

OFFICIAL JOURNAL OF THE AMERICAN ACADEMY OF PEDIATRICS

\title{
Explaining Change in Quality of Life of Children and Adolescents With Anorectal Malformations or Hirschsprung Disease
}

Esther E. Hartman, Frans J. Oort, Daniel C. Aronson, Marianne J.G. Hanneman, Ernest van Heurn, Zacharias J. de Langen, Gerard C. Madern, Paul N.M.A. Rieu, David C. van der Zee, Nic Looyaard, Marina van Silfhout-Bezemer and Mirjam A.G. Sprangers

Pediatrics 2007;119; 374

DOI: $10.1542 /$ peds.2006-0212

The online version of this article, along with updated information and services, is located on the World Wide Web at: http://pediatrics.aappublications.org/content/119/2/e374.full.html

PEDIATRICS is the official journal of the American Academy of Pediatrics. A monthly publication, it has been published continuously since 1948. PEDIATRICS is owned, published, and trademarked by the American Academy of Pediatrics, 141 Northwest Point Boulevard, Elk Grove Village, Illinois, 60007. Copyright () 2007 by the American Academy of Pediatrics. All rights reserved. Print ISSN: 0031-4005. Online ISSN: 1098-4275.

\section{American Academy of Pediatrics}




\title{
Explaining Change in Quality of Life of Children and Adolescents With Anorectal Malformations or Hirschsprung Disease
}

\author{
Esther E. Hartman, PhD ${ }^{a, b}$, Frans J. Oort, PhD b, Daniel C. Aronson, MD, PhDa, Marianne J. G. Hanneman, MA ${ }^{a, b}$, Ernest van Heurn, MD, PhDc, \\ Zacharias J. de Langen, MD, PhDd, Gerard C. Madern, MDe, Paul N. M. A. Rieu, MD, PhDf, David C. van der Zee, MD, PhDg, Nic Looyaardh, \\ Marina van Silfhout-Bezemer, MDi, Mirjam A. G. Sprangers, PhD ${ }^{\mathrm{b}}$
}

aPediatric Surgical Centers of Amsterdam, Emma Children's Hospital Academic Medical Centre/NU Medical Center, Amsterdam, Netherlands; bDivision of Medical Psychology,

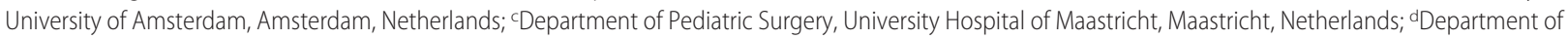
Pediatric Surgery, University Hospital of Groningen, Groningen, Netherlands; eDepartment of Pediatric Surgery, University Hospital of Rotterdam, Rotterdam, Netherlands; fDepartment of Pediatric Surgery, University Hospital of Nijmegen, Nijmegen, Netherlands; 9Department of Pediatric Surgery, University Hospital of Utrecht, Utrecht, Netherlands; 'Patient Society of Anorectal Malformations, Nijverdal, Netherlands; and Patient Society of Hirschsprung's Disease, Hilversum, Netherlands

The authors have indicated they have no financial relationships relevant to this article to disclose.

\section{ABSTRACT}

OBJECTIVES. The purpose of this work was to examine changes in quality of life, disease-specific functioning, and psychosocial competencies of children and adolescents (8-16 years of age) with anorectal malformations or Hirschsprung disease and to identify predictors of change in quality of life by testing an explanatory model in which background variables explained changes in quality of life via changes in disease-specific functioning and psychosocial competencies.

METHODS. Questionnaires were administered to 129 patients with anorectal malformations and 121 patients with Hirschsprung disease within a 3-year interval. Clinical and sociodemographic background variables were measured on the first occasion. Quality of life (physical and mental), disease-specific functioning (defecation-related), and psychosocial competencies (self-esteem, athletic competencies, and school attitude) were measured on both occasions.

RESULTS. Patients improved in disease-specific functioning and mental quality of life. Changes in quality of life were indeed explained by the explanatory model. Among other things, the results indicated that patients with a severe form of the disease or with additional congenital diseases showed worsening of school attitude, which in turn affected change in mental quality of life negatively.

CONCLUSIONS. Children and adolescents with anorectal malformations or Hirschsprung disease reported better quality of life over time. To improve and maintain an optimal level of children's and adolescents' quality of life, it is important to direct treatment both to reducing symptoms and enhancing psychosocial competencies, in particular by paying attention to school attitude.

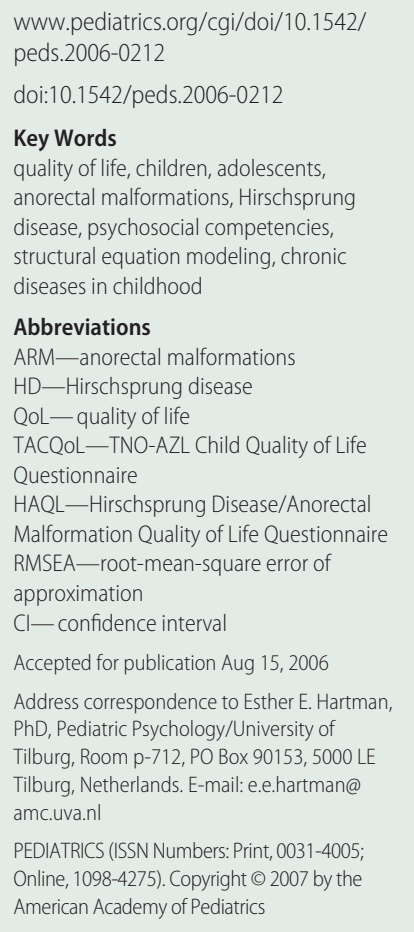


C HILDREN AND ADOLESCENTS with anorectal malformations (ARM) or Hirschsprung disease (HD) have to cope with substantial functional problems, such as severe constipation and fecal incontinence, which often remain after neonatal surgery and affect quality of life (QoL). ${ }^{1-5}$ The ultimate goal of treatment of patients with ARM or HD has moved from mere survival to alleviating symptoms and improving QoL.

QoL has become clearly established as an important end point in medical care. ${ }^{6}$ This is especially true for chronic diseases for which complete recovery is unlikely. Although definitions of QoL vary widely, there is consensus about 2 central aspects. First, QoL should be assessed from the patient's perspective whenever possible. ${ }^{7}$ Second, QoL should be regarded as a multidimensional construct incorporating at least 3 broad domains that can be affected by one's disease or treatment, including physical, mental, and social functioning..$^{8,9}$

In a cross-sectional study, Poley et $\mathrm{al}^{1}$ found that the QoL of young children (aged 1-4 years) with ARM was poor. Parents reported that their young children with ARM more often had stomachache; more eating, appetite and sleeping problems; less positive emotions; more anxiety; and less vitality than was reported by parents of healthy peers. However, in the same study, children aged 5 to 15 years showed only a little more impairment than healthy children did in some of the QoL domains, which may indicate that the QoL of patients with ARM improved considerably with increasing age. Remarkably, they found that functional status was not a good predictor of QoL in children and adolescents. Hartman et al ${ }^{10}$ found similar results in a study with an adult population; it seemed that psychosocial functioning was the most important predictor of the QoL of patients with ARM or HD, whereas fecal incontinence and constipation had almost no effect on patient QoL.

However, to date, no longitudinal QoL studies of children and adolescents with ARM or HD have been reported. This lack of longitudinal research limits the understanding of the extent to which the QoL of children and adolescents changes over time and of factors predicting such changes.

Study of factors affecting changes in QoL provides insight into how physicians and other health care pro- viders may help to improve and maintain an optimal level of patient QoL. It is, therefore, important to examine which variables affect patient QoL and how. In the present study, a group of children and adolescents with ARM or HD, aged 8 to 16 years, was assessed 2 times with 3 years in between. To explain possible changes in QoL, we used an explanatory model based on the Wilson and Cleary model. ${ }^{11}$ We hypothesized that change in QoL is predicted by change in disease-specific functioning and in psychosocial competencies for which changes, in turn, are affected by several sociodemographic and clinical background characteristics (Fig 1). QoL refers to all aspects of health and well-being irrespective of the underlying disease, whereas disease-specific functioning refers to disease-related physical symptoms (eg, fecal incontinence) and associated emotions (eg, feelings of shame). Increasing psychosocial competencies, such as self-esteem, athletic competencies, and school attitude, is hypothesized to improve QoL.

The goals of the study were to investigate whether QoL, disease-specific functioning, and psychosocial competencies of children and adolescents with ARM or HD changed over time and to test the extent to which background characteristics of these children and adolescents explained changes in QoL via change in disease-specific functioning and in psychosocial competencies.

\section{METHODS}

\section{Subjects}

In December 1998, all 722 of the known Dutch patients between the ages of 8 and 16 years with ARM or HD were selected from the 6 Dutch Pediatric Surgical Centers and from the 2 patient societies for ARM or HD. Not included were patients who lacked basic proficiency in Dutch, were mentally retarded and/or had Down syndrome, had a cloaca, were untraceable, or had died $(n=$ 231). A first set of questionnaires was sent to 491 patients (276 with ARM and 215 with HD), which was completed and returned by $316(64 \%)$ of the patients (164 [59\%] with ARM and 152 [71\%] with HD). Informed consent concerning permission of studying data of the medical charts accompanied the first questionnaire. In December 2001, patients who completed the

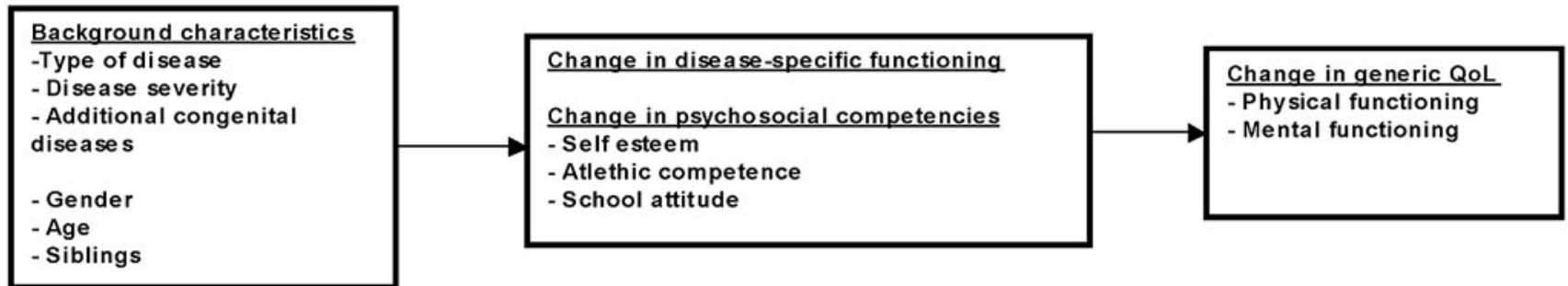

FIGURE 1

Explanatory model of changes in disease-specific functioning, psychosocial competencies, and QoL. 
first questionnaire were sent a second set of questionnaires. To control for seasonal variation in fecal continence problems, the second assessment was conducted in the same month as the first assessment. The study was approved by the medical ethics committees of all 6 participating pediatric surgical centers.

\section{Procedure}

Questionnaires were completed on 2 occasions with a 3-year interval. QoL, disease-specific functioning, and psychosocial competencies were measured on both occasions. The background characteristics disease severity, presence of additional congenital anomalies, stoma, surgery, age at surgery, gender, age, and siblings were assessed during the first measurement occasion.

\section{Measures}

Most instruments in QoL research can be classified as either generic or disease specific. The generic instruments intend to measure all aspects of health and wellbeing irrespective of the underlying disease and enable comparisons across different disease groups and with healthy peers. However, a limitation is that the generic instruments do not measure aspects that are of particular relevance of specific disease groups, such as disease symptoms. Conversely, disease-specific measures examine the functioning and symptoms of specific disease groups. Disease-specific measures may be more responsive to clinical changes than generic measures. ${ }^{12}$ As is common in QoL research, we decided to include both types of questionnaires.

\section{Quality of Life}

QoL was measured with the TNO-AZL Child Quality of Life Questionnaire (TACQoL). ${ }^{13,14}$ This questionnaire has been shown to be a reliable and valid instrument for measuring QoL in children and adolescents between the age of 8 and 16 years. We used 2 different versions of the TACQoL, a child form (8-11 years) ${ }^{13}$ and an adolescent form (12-16 years). ${ }^{14}$ Both versions consist of 56 identical items, but the adolescents' form is composed of 31 additional items that were not applicable for younger children, such as questions about homework, body image, and worries about the future. In the present study, we used only the 56 identical items to enable comparison of children and adolescents. We added a sentence in the introduction of the questionnaire that explained the "childish" character of some of the topics, because we had to use exactly the same questions as 3 years before. These 56 items measure 6 scales of QoL: 4 health-related functioning scales and 2 scales representing respondents' negative and positive emotional state. On each item of the health-related functioning scales, the respondent indicates whether or not a specific problem occurred in the past few weeks, with 3 response options: never, occasionally, and often. If a problem occurred, the respon- dent was asked to indicate how he/she felt about this problem: fine, not so good, quite bad, and bad. For each item, the 2 responses were combined into a single item score, ranging from 0 to 4 (never, 4; occasionally or often in combination with fine, 3; not so good, 2; quite bad, 1 ; bad, 0). With the emotion scales, respondents indicated on a Likert scale whether the presented feeling occurred recently in the past few weeks (never, occasionally, or often). Item scores of these 2 scales range from 0 to 2 . To reduce the number of outcome variables, we summarized the 6 scales of the TACQoL by 2 components, based on content and on principal component analysis: physical QoL (pain and symptoms, basic motor functioning, and cognition) and mental QoL (interaction with parents and peers, experience of positive and negative emotions, and cognition).

\section{Disease-Specific Functioning}

Disease-specific functioning was measured with the Hirschsprung Disease/Anorectal Malformation Quality of Life Questionnaire (HAQL), ${ }^{15}$ consisting of 38 items for children and 2 additional items about sexuality for adolescents. To compare the data of the children and the adolescents, we did not use the sexuality items. The item scores range from 1 to 4 (1, never; 2 , sometimes; 3 , often; 4 , very often). Scores were recoded so that higher scores indicate a higher level of functioning. The 38 items of the HAQL were combined to form 9 subscales, ${ }^{15}$ but we used only 5 with reasonable score distribution. As principal component analysis of these 5 HAQL scales yielded only 1 factor with an eigen value $>1$, accounting for $>40 \%$ of all variance, we summed item scores into a single overall HAQL score, representing disease-specific functioning, covering fecal incontinence (presence of diarrhea and fecal incontinence), constipation (physical symptoms), and disease-specific psychosocial functioning (emotional functioning and body image). Consequently, we summed up these scores to form 1 scale that showed good reliability, with Cronbach's $\alpha$ ranging from .80 to .90 for different disease groups (ARM and HD) and age groups (children and adolescents).

\section{Psychosocial Competencies}

Psychosocial competencies were assessed with the SelfPerception Profile, ${ }^{16,17}$ consisting of 36 items for children and 4 additional items for adolescents, which measure perceived competencies. To compare the data of the children and the adolescents, we used only the 36 items that were common to both versions, which were all formulated as pairs of opposite assertions, for example, "some children/adolescents are satisfied with their appearance," with 2 response options: completely true or hardly true. The opposite assertion is formulated like "other children/adolescents would like to look different," with the same response options. The items were combined to form 6 subscales: scholastic competence, 
social acceptance, athletic competence, physical appearance, behavioral conduct, and global self-worth. Each answer was scored between 1 for most competent (completely true) and 4 for least competent (completely true for the opposite pair). Scores, ranging from 1 to 4 , were coded so that higher scores indicate a higher level of functioning. Through principal component analysis we summarized the 6 competence scales by 3 components, self-esteem (physical appearance and global self-worth), athletic competence (athletic competence and social acceptance), and school attitude (scholastic competence, behavioral conduct, and social acceptance).

\section{Background Characteristics}

Clinical variables were extracted from medical charts and included disease severity (mild versus severe), presence of additional congenital anomalies (yes versus no), presence of a permanent stoma (yes versus no), surgery (yes versus no), and age at surgery. For ARM, "mild" versus "severe" referred to low defects (bucket handle, covered anus, anterior displaced anus, and perineal or vestibular fistula) versus more complex defects (urethral, vesical or vaginal fistula, or no fistula). ARM often occurs in combination with other congenital problems, which are frequently clustered in the "VACTERL association." Every letter of VACTERL refers to congenital anomalies, including vertebral, anorectal, cardial, tracheo, esophageal, renal, and limb defects. ${ }^{18}$ For HD, "mild disease" was defined as aganglionosis of a common (or usual) segment (rectum or sigmoid), and "severe disease" referred to aganglionosis of a long segment (colon descendens, colon transversum, colon ascendens, or ileum). Sociodemographic characteristics included gender (male versus female), age, and the number of siblings $(0,1$, or $>1)$.

\section{Statistical Analyses}

\section{Sample Characteristics}

We tested for differences in clinical and sociodemographic characteristics between disease groups (ARM and HD) and age groups (children and adolescents). $\chi^{2}$ tests were used for discrete variables (gender, siblings, disease severity, presence of additional congenital anomalies, stoma, and surgery) and $t$ tests for continuous variables (age and age at surgery). Differences in QoL, disease-specific functioning, and psychosocial competencies between disease and age groups were also tested with $t$ tests. The same analyses were performed to test for differences between children and adolescents who were included in both measurements (respondents) and children and adolescents who were included in the first measurement but not in the second measurement (nonrespondents). The level of significance was set at $5 \%$.

\section{Change}

To examine changes in disease-specific functioning, psychosocial competencies, and in QoL in the 4 groups (ARM and HD $\times$ children and adolescents), repeatedmeasures analysis of variance with type of disease and age group as independent factors was used. Scores are scaled to overall mean at 0 and SD at 1 at the first measurement occasion. In this way, means at the second measurement occasion can be interpreted as change scores, and the sizes of mean change can be interpreted according to Cohen' $\mathrm{s}^{19}$ effect sizes $\mathrm{d}$, which facilitate the interpretation of the differences among type of disease, age group, and time. According to Cohen, ${ }^{19}$ effect sizes d of $0.20,0.50$, and 0.80 can be considered small, medium, and large, respectively.

\section{Predicting Change}

The relationships between change and possible predictors of change are investigated through structural equation modeling. In structural equation modeling, the covariance structure that follows from the proposed model is fitted to the observed covariances. ${ }^{20}$ Change in the variables physical QoL, mental QoL, disease-specific functioning, self-esteem, athletic competencies, and school attitude was operationalized by subtracting the effects of the first-occasion components from the second-occasion components. In this way, we accounted for initial differences and for regression to the mean artifacts. The maximum likelihood estimation method yields estimates of the regression coefficients in the model, SEs, and a $\chi^{2}$ test of overall goodness of fit. ${ }^{20} \mathrm{An}$ alternative fit measure is the root-mean-square error of approximation (RMSEA). According to a generally accepted rule of thumb, ${ }^{21}$ RMSEA values $<0.08$ indicate reasonable fit, and values $<0.05$ indicate close fit. In addition to overall goodness of fit, component fit was evaluated by inspecting standardized discrepancies (between observed and expected correlations) and LISREL's modification indices. ${ }^{22}$

To check whether the different samples of ARM and HD patients and of children and adolescents could be combined for the analysis of predicting change, we tested whether the relationships between research variables for these groups were similar or not. Structural equation modeling showed that the correlation matrices of the age groups (RMSEA: 0.050; 90\% confidence interval [CI]: $0.026-0.069)$ and the 2 disease groups (RMSEA: 0.044; 90\% CI: 0.016-0.065) were essentially equivalent, so we combined age and disease groups for the analysis of predicting change to obtain the additional advantage of a larger sample size (increased power and higher precision). Despite equivalent relationships between research variables, patients with ARM and HD and children and adolescents may change differently in disease specific functioning, psychosocial competencies, and QoL. We therefore included type of disease (ARM or 
HD) and age among the predictor variables. Relationships between predictor variables and changes in outcome variables were expressed as standardized regression coefficients or correlation coefficients and tested through Wald tests. ${ }^{20}$

\section{RESULTS}

\section{Sample Characteristics}

Of the 164 patients with ARM and the 152 patients with $\mathrm{HD}$ at the first measurement occasion, 129 ARM patients $(79 \%)$ and $121 \mathrm{HD}$ patients $(80 \%)$ also completed the questionnaires of the second occasion. Patient characteristics are presented in Table 1.

When comparing ARM and HD patients, the results showed a larger proportion of boys in the HD group $(P=$ .04) and a larger proportion of ARM patients with a severe form of the disease $(P=.00)$ and additional congenital anomalies (because of the VACTERL association; $P=.00)$. Moreover, children and adolescents with ARM had surgery over $>4$ months earlier than patients with HD $(P=.02)$. None of the comparisons between ARM and HD patients in QoL, disease-specific functioning, or psychosocial competencies resulted in significant differences (Table 1).

When comparing children and adolescents, the results showed a larger proportion of children with additional congenital anomalies $(P=.02)$, and children had surgery $>4$ months earlier than adolescents $(P=.04)$. In addition, significant differences were found in selfesteem $(P=.00)$ and athletic competencies $(P=.02)$, on which children reported to do better (Table 1$)$.

Table 2 shows comparison of children and adolescents

TABLE 1 Patient Characteristics of Children and Adolescents With ARM or HD Who Responded at Both Measurement Occasions

\begin{tabular}{|c|c|c|c|c|c|c|c|c|c|c|}
\hline \multirow[t]{3}{*}{ Characteristic } & \multicolumn{4}{|c|}{ ARM } & \multicolumn{4}{|c|}{$\mathrm{HD}$} & \multicolumn{2}{|c|}{ Comparisons } \\
\hline & \multicolumn{2}{|c|}{ Children $(n=76)$} & \multicolumn{2}{|c|}{ Adolescents $(n=53)$} & \multicolumn{2}{|c|}{ Children $(n=65)$} & \multicolumn{2}{|c|}{ Adolescents $(n=56)$} & \multirow{2}{*}{$\begin{array}{c}P, \text { Disease } \\
\text { Groups }\end{array}$} & \multirow{2}{*}{$\begin{array}{l}P, \text { Age } \\
\text { Groups }\end{array}$} \\
\hline & $n(\%)$ & Mean (SD) & $n(\%)$ & Mean (SD) & $n(\%)$ & Mean (SD) & $n(\%)$ & Mean (SD) & & \\
\hline \multicolumn{11}{|l|}{ Sociodemographic characteristics } \\
\hline Gender & & & & & & & & & $.04^{a}$ & $.07^{a}$ \\
\hline Male & $52(68)$ & & $39(74)$ & & $49(75)$ & & $50(89)$ & & & \\
\hline Female & $24(32)$ & & $14(26)$ & & $16(25)$ & & $6(11)$ & & & \\
\hline Age, y & & $9.5(1.1)$ & & $13.9(1.5)$ & & $9.2(1.1)$ & & $14.0(1.4)$ & $.69^{\mathrm{b}}$ & NA \\
\hline Siblings & & & & & & & & & $.98^{\mathrm{a}}$ & $.63^{\mathrm{a}}$ \\
\hline No & $3(4)$ & & $1(2)$ & & $1(2)$ & & $3(5)$ & & & \\
\hline Yes, 1 & $41(54)$ & & $24(45)$ & & $33(51)$ & & $27(48)$ & & & \\
\hline Yes, $>1$ & $31(41)$ & & $27(51)$ & & $30(46)$ & & $26(46)$ & & & \\
\hline Missing & $1(1)$ & & $1(2)$ & & $1(2)$ & & $0(0)$ & & & \\
\hline \multicolumn{11}{|l|}{ Clinical characteristics } \\
\hline Disease severity & & & & & & & & & $.00^{\mathrm{a}}$ & $.81^{\mathrm{a}}$ \\
\hline Mild & $26(34)$ & & $21(40)$ & & $46(71)$ & & $37(66)$ & & & \\
\hline Severe & $42(55)$ & & $25(47)$ & & $15(23)$ & & $18(32)$ & & & \\
\hline Missing & $8(11)$ & & $7(13)$ & & $4(6)$ & & $1(2)$ & & & \\
\hline Additional congenital anomalies & & & & & & & & & $.00^{\mathrm{a}}$ & $.02^{\mathrm{a}}$ \\
\hline Yes & $40(53)$ & & $21(40)$ & & $9(14)$ & & $3(5)$ & & & \\
\hline No & $28(37)$ & & $25(47)$ & & $52(80)$ & & $52(93)$ & & & \\
\hline Missing & $8(11)$ & & $7(13)$ & & $4(6)$ & & $1(2)$ & & & \\
\hline \multicolumn{11}{|l|}{ Stoma } \\
\hline Yes & $1(1)$ & & $4(8)$ & & $3(5)$ & & $2(4)$ & & NA & NA \\
\hline No & $75(99)$ & & $49(93)$ & & $62(95)$ & & $54(96)$ & & & \\
\hline \multicolumn{11}{|l|}{ Surgery } \\
\hline Yes & $62(82)$ & & $34(64)$ & & $60(92)$ & & $51(91)$ & & NA & NA \\
\hline No & $1(1)$ & & & & $1(2)$ & & $1(2)$ & & & \\
\hline Missing & $13(17)$ & & $19(36)$ & & $4(6)$ & & $4(7)$ & & & \\
\hline Age at surgery, mo & & $8.6(8.0)$ & & $9.8(13.7)$ & & $10.9(12.9)$ & & $16.6(19.7)$ & $.02^{\mathrm{b}}$ & $.04^{\mathrm{b}}$ \\
\hline \multicolumn{11}{|l|}{ Psychological variables } \\
\hline \multicolumn{11}{|l|}{ Generic QoL } \\
\hline Physical QoL & & $34.7(4.2)$ & & $35.1(3.4)$ & & $35.1(3.4)$ & & $34.1(5.4)$ & $.78^{\mathrm{b}}$ & $.50^{\mathrm{b}}$ \\
\hline Mental QoL & & $23.1(2.9)$ & & $23.3(2.9)$ & & $22.9(3.1)$ & & $23.2(3.2)$ & $.66^{\mathrm{b}}$ & $.55^{\mathrm{b}}$ \\
\hline Disease-specific functioning & & $18.5(1.3)$ & & $18(1.3)$ & & $18.3(1.3)$ & & $18.3(1.7)$ & $.14^{\mathrm{b}}$ & $.37^{b}$ \\
\hline \multicolumn{11}{|l|}{ Psychosocial competencies } \\
\hline Self-esteem & & $3.6(0.5)$ & & $3.3(0.7)$ & & $3.6(0.6)$ & & $3.4(0.7)$ & $.87^{\mathrm{b}}$ & $.00^{\mathrm{b}}$ \\
\hline School attitude & & $3.6(0.6)$ & & $3.5(0.6)$ & & $3.7(0.7)$ & & $3.5(0.6)$ & $.81^{\mathrm{b}}$ & $.08^{\mathrm{b}}$ \\
\hline Athletic competence & & $3.1(0.8)$ & & $2.9(0.7)$ & & $3.2(0.7)$ & & $2.8(0.8)$ & $.43^{\mathrm{b}}$ & $.02^{\mathrm{b}}$ \\
\hline
\end{tabular}

NA indicates not applicable.

a $P$ values associated with $\chi^{2}$ test.

$\mathrm{b} P$ values associated with $t$ test. 
TABLE 2 Patient Characteristics of Patients Who Were Included in Both Measurements (Respondents) and of Those Who Were Included in the First Measurement but Not in the Second Measurement (Nonrespondents)

\begin{tabular}{|c|c|c|c|c|c|}
\hline \multirow[t]{2}{*}{ Characteristic } & \multicolumn{2}{|c|}{ Respondents $(n=250)$} & \multicolumn{2}{|c|}{ Nonrespondents $(n=66)$} & \multirow[t]{2}{*}{$P$} \\
\hline & $n(\%)$ & Mean (SD) & $n(\%)$ & Mean (SD) & \\
\hline \multicolumn{6}{|l|}{ Sociodemographic characteristics } \\
\hline Age groups & & & & & $.03^{a}$ \\
\hline Children & $141(56)$ & & $27(41)$ & & \\
\hline Adolescents & $109(44)$ & & $39(59)$ & & \\
\hline Gender & & & & & $.02^{\mathrm{a}}$ \\
\hline Male & $190(76)$ & & $41(62)$ & & \\
\hline Female & $60(24)$ & & $25(38)$ & & \\
\hline Age & & & & & $.00^{\mathrm{b}}$ \\
\hline Mean (SD) age, y & & $11.4(2.6)$ & & $12.5(2.7)$ & \\
\hline Siblings & & & & & $.04^{\mathrm{a}}$ \\
\hline No & $8(3)$ & & $6(9)$ & & \\
\hline Yes, 1 & $125(50)$ & & $25(38)$ & & \\
\hline Yes, $>1$ & $114(46)$ & & $35(53)$ & & \\
\hline Missing & $3(1)$ & & $0(0)$ & & \\
\hline \multicolumn{6}{|l|}{ Clinical characteristics } \\
\hline Type of disease & & & & & $.84^{\mathrm{a}}$ \\
\hline ARM & $129(52)$ & & $35(53)$ & & \\
\hline$H D$ & $121(48)$ & & $31(47)$ & & \\
\hline Disease severity & & & & & $.17^{a}$ \\
\hline Mild & $130(52)$ & & $41(62)$ & & \\
\hline Severe & $100(40)$ & & $21(32)$ & & \\
\hline Missing & $20(8)$ & & $4(6)$ & & \\
\hline Additional congenital anomalies & & & & & $.18^{\mathrm{a}}$ \\
\hline Yes & $73(29)$ & & $14(21)$ & & \\
\hline No & $157(63)$ & & $47(71)$ & & \\
\hline Missing & $20(8)$ & & $5(8)$ & & \\
\hline Stoma & & & & & NA \\
\hline Yes & $10(4)$ & & $2(3)$ & & \\
\hline No & $240(96)$ & & $64(97)$ & & \\
\hline Surgery & & & & & NA \\
\hline Yes & $207(83)$ & & $53(80)$ & & \\
\hline No & $3(1)$ & & $2(3)$ & & \\
\hline Missing & $40(16)$ & & $11(17)$ & & \\
\hline Age at surgery & & & & & $.32^{\mathrm{b}}$ \\
\hline Mean age in months (SD) & & $11.4(14.2)$ & & $9.4(10.6)$ & \\
\hline \multicolumn{6}{|l|}{ Psychological variables } \\
\hline \multicolumn{6}{|l|}{ Generic QoL } \\
\hline Physical QoL & & $34.7(4.2)$ & & $33.5(6.1)$ & $.06^{\mathrm{b}}$ \\
\hline Mental QoL & & $23.1(3.1)$ & & $22.2(3.6)$ & $.03^{b}$ \\
\hline Disease-specific functioning & & $18.5(1.4)$ & & $18.2(2.1)$ & $.28^{\mathrm{b}}$ \\
\hline \multicolumn{6}{|l|}{ Psychosocial competencies } \\
\hline Self-esteem & & $3.5(0.6)$ & & $3.4(0.7)$ & $.37^{\mathrm{b}}$ \\
\hline School attitude & & $3.6(0.6)$ & & $3.4(0.6)$ & $.05^{\mathrm{b}}$ \\
\hline Athletic competence & & $3.1(0.7)$ & & $2.9(0.8)$ & $.41^{\mathrm{b}}$ \\
\hline
\end{tabular}

who were included in the first measurement (respondents) with children and adolescents who were included in the first measurement but not in the second measurement (nonrespondents). Results showed that children, boys, and patients with more siblings more often responded to both measurement occasions than adolescents $(P=.03)$, girls $(P=.02)$, or patients with 1 or without siblings $(P=.04)$, respectively. However, no differences were found in the clinical characteristics (type of disease, disease severity, additional congenital anomalies, stoma, and age at surgery). On the psychological variables respondents scored better, but only mental QoL comparison reached statistical significance.

\section{Change}

On average, all of the patients improved in diseasespecific functioning $(d=0.22 ; P=.00)$ and mental QoL $(d=0.15 ; P=.01)$. In physical QoL, only the adoles- 
cents improved $(d=0.16)$, whereas children deteriorated $(d=-0.14$; interaction effect age by time: $P=$ $.02)$. The results showed no change in psychosocial competencies. However, on both measurement occasions, adolescents reported a significantly lower level of selfesteem than children $(d=0.35 ; P=.00$; Table 3$)$.

\section{Predicting Change}

The model described in Fig 1, denoted as "explanatory model," was fitted to the data. The $\chi^{2}$ measure of overall goodness of fit was $33.46\left(\chi^{2}: 20 ; P=.030\right)$, and the hypotheses of exact fit was rejected, but the RMSEA measure was 0.052 , and the $90 \%$ CI ranged from 0.016 to 0.082 , indicating satisfactory fit. Table 4 presents the standardized regression coefficients of the model.

All of the continuous variables are standardized to $z$ scores (a higher score means better functioning), and all of the dichotomous variables are binary coded as 0 and 1, respectively. Effects of dichotomous predictor variables on the change variables can be interpreted as follows: a dichotomous predictor variable (eg, disease severity or type of disease) that negatively affects a change variable indicates that patients with a severe form of the disease or those with HD, coded as 1, did not improve in the concerning change variable. Similarly, patients who were coded as 0 on these predictor variables, that is, patients with a mild form or patients with ARM, with the same negative effects on the change variables, deteriorated less or even improved in the concerning change variable. An example will facilitate the interpretation of Table 4. The first part contains the effects of the predictor variables on the change in the mediating variables, where we see that the effect of disease severity on change in disease-specific functioning was -0.21 , which means that a severe form of the disease negatively affected change in disease-specific functioning with 0.21 SD. The group as a whole improved 0.22 (Table 3, last column), so, in effect, the severely affected patients did not improve. The second part of Table 4 contains the effects of changes in the mediating factors on changes in the generic QoL factors, where we see that change in disease-specific functioning affected change in physical QoL by 0.15 .

Athletic competencies at the first measurement occasion positively affected change in disease-specific functioning $(\beta=.14)$ and change in self-esteem $(\beta=.17)$. Patients with HD and female patients deteriorated more in self-esteem than patients with ARM $(\beta=-.12)$ and male patients $(\beta=-.21)$. Girls also deteriorated in athletic competencies $(\beta=-.20)$. A severe form of the disease and the presence of additional congenital anomalies negatively changed school attitude over time $(\beta=$ -.11 and $\beta=-.12$, respectively). In turn, change in physical QoL was positively affected by change in disease-specific functioning $(\beta=.15)$, change in self-esteem $(\beta=.25)$, and change in school attitude $(\beta=.14)$. Change in mental QoL was positively affected by changes in self-esteem $(\beta=.26)$ and school attitude $(\beta$ $=.43$ ).

In addition, significant correlations were found among the mediating change variables: an improvement in disease-specific functioning was associated with an improvement in self-esteem $(r=0.28)$, school attitude $(r$ $=0.14)$, and athletic competencies $(r=0.19$; data not shown). The last row of Table 4 shows that $44 \%$ of all change in physical QoL and 59\% of all change in mental QoL was explained by the model.

\section{DISCUSSION}

Because medical training, practice, and research are traditionally organized around disease categories, it is not surprising that from the physicians' point of view, ARM and HD need to be examined separately. However, it is not clear whether classifying patients by disease is appropriate when examining the broader issues of the effects of the illness on the patient. ${ }^{1}$ After all, both patients with ARM and HD have to deal with similar physical problems, such as chronic fecal incontinence and

TABLE 3 Change in QoL, Disease-Specific Functioning, and Psychosocial Competencies for Children and Adolescents With ARM or HD

\begin{tabular}{|c|c|c|c|c|c|c|c|c|c|c|}
\hline \multirow[t]{3}{*}{ Variable } & \multicolumn{5}{|c|}{ Measurement Occasion I, Mean (SD) } & \multicolumn{5}{|c|}{ Measurement Occasion II, Mean (SD) } \\
\hline & \multicolumn{2}{|c|}{ ARM } & \multicolumn{2}{|c|}{ HD } & \multirow{2}{*}{$\begin{array}{c}\text { Total } \\
(N=250)\end{array}$} & \multicolumn{2}{|c|}{ ARM } & \multicolumn{2}{|c|}{$\mathrm{HD}$} & \multirow{2}{*}{$\begin{array}{c}\text { Total } \\
(N=250)\end{array}$} \\
\hline & $\begin{array}{l}\text { Children } \\
(n=76)\end{array}$ & $\begin{array}{c}\text { Adolescents } \\
(n=53)\end{array}$ & $\begin{array}{l}\text { Children } \\
(n=65)\end{array}$ & $\begin{array}{c}\text { Adolescents } \\
(n=56)\end{array}$ & & $\begin{array}{l}\text { Children } \\
(n=76)\end{array}$ & $\begin{array}{c}\text { Adolescents } \\
(n=53)\end{array}$ & $\begin{array}{l}\text { Children } \\
(n=65)\end{array}$ & $\begin{array}{c}\text { Adolescents } \\
\quad(n=56)\end{array}$ & \\
\hline \multicolumn{11}{|l|}{ Generic QoL } \\
\hline Physical QoL & $-0.01(1.01)$ & $0.06(0.82)$ & $0.09(0.82)$ & $-0.15(1.29)$ & $0.00(1.00)$ & $-0.20(1.18)$ & $0.06(0.80)$ & $0.01(1.00)$ & $0.16(1.02)$ & $-0.01(1.02)$ \\
\hline Mental QoL & $0.01(0.97)$ & $0.05(0.95)$ & $-0.07(1.02)$ & $0.03(1.08)$ & $0.00(1.00)$ & $0.05(1.03)$ & $0.16(0.94)$ & $0.16(0.94)$ & $0.26(0.88)$ & $0.15(0.95)^{a}$ \\
\hline Disease-specific functioning & $0.01(0.97)$ & $0.21(0.89)$ & $-0.14(0.95)$ & $-0.04(1.18)$ & $0.00(1.00)$ & $0.18(0.83)$ & $0.37(0.67)$ & $0.21(0.76)$ & $0.17(0.84)$ & $0.22(0.78)^{\mathrm{a}}$ \\
\hline \multicolumn{11}{|l|}{ Psychosocial competences } \\
\hline Self-esteem & $0.22(0.83)$ & $-0.36(0.99)$ & $0.19(1.02)$ & $-0.18(1.09)$ & $0.00(1.00)$ & $0.08(1.04)$ & $-0.36(1.11)$ & $-0.19(1.13)$ & $-0.18(1.06)$ & $-0.14(1.09)$ \\
\hline School attitude & $0.10(1.01)$ & $-0.16(0.86)$ & $0.14(1.17)$ & $-0.13(0.87)$ & $0.00(1.00)$ & $0.01(1.00)$ & $-0.10(0.82)$ & $-0.09(0.97)$ & $-0.04(0.88)$ & $-0.05(0.93)$ \\
\hline & $0.01(1.04)$ & $-0.18(0.86)$ & $0.27(1.01)$ & $-0.16(1.01)$ & $0.00(1.00)$ & $-0.05(1.05)$ & $-0.28(0.83)$ & $0.09(0.99)$ & $0.04(0.91)$ & $-0.04(0.96)$ \\
\hline
\end{tabular}

Scores are scaled to overall mean of 0 and SD of 1 at the first measurement occasion. In this way means at the second measurement occasion can be interpreted as change scores, and the sizes of mean change can be interpreted according to Cohen's 19 effect sizes: "small" (0.20), "medium" (0.50), and "large" (0.80).

a $P<.05$ for time effects in repeated-measures analysis of variance. 
TABLE 4 Regression Coefficients and Percentages of Explained Variance in the Explanatory Model of Predictors of Change in QoL of ARM and HD Patients

\begin{tabular}{|c|c|c|c|c|c|c|}
\hline Predictors of Change & $\begin{array}{l}\text { Change in } \\
\text { Disease-Specific } \\
\text { Functioning }(P)\end{array}$ & $\begin{array}{l}\text { Change in } \\
\text { Self-esteem } \\
(P)\end{array}$ & $\begin{array}{c}\text { Change in } \\
\text { Athletic Competence } \\
(P)\end{array}$ & $\begin{array}{c}\text { Change in } \\
\text { School Attitude } \\
(P)\end{array}$ & $\begin{array}{l}\text { Change in } \\
\text { Physical QoL } \\
(P)\end{array}$ & $\begin{array}{l}\text { Change in } \\
\text { Mental QoL } \\
(P)\end{array}$ \\
\hline \multicolumn{7}{|l|}{$\begin{array}{c}\text { Effects of the predictor variables on } \\
\text { the change variables }\end{array}$} \\
\hline \multicolumn{7}{|l|}{ Clinical variables } \\
\hline Type of disease (HD) & $-0.11(.09)$ & $-0.12(.04)^{a}$ & $0.02(.69)$ & $-0.09(.09)$ & & \\
\hline Disease-severity (severe) & $-0.21(.00)^{\mathrm{a}}$ & $-0.01(.80)$ & $0.04(.40)$ & $-0.11(.04)^{a}$ & & \\
\hline Congenital disease (yes) & $0.07(.24)$ & $0.09(.12)$ & $0.07(.20)$ & $-0.12(.03)^{\mathrm{a}}$ & & \\
\hline \multicolumn{7}{|l|}{ Sociodemographic variables } \\
\hline Gender (female) & $-0.01(.99)$ & $-0.21(.00)^{\mathrm{a}}$ & $-0.20(.00)^{\mathrm{a}}$ & $0.05(.31)$ & & \\
\hline Age & $-0.01(.81)$ & $-0.07(.24)$ & $0.00(.92)$ & $0.04(.45)$ & & \\
\hline Siblings (yes) & $-0.03(.56)$ & $0.07(.21)$ & $0.03(.52)$ & $-0.03(.57)$ & & \\
\hline Psychological predictor variables & b & & & & & \\
\hline Disease-specific functioning & & $0.11(.08)$ & $0.02(.77)$ & $0.00(.95)$ & & \\
\hline Self-esteem & $-0.02(.76)$ & $b$ & $-0.07(.22)$ & $-0.05(.36)$ & & \\
\hline Athletic competencies & $0.14(.03)^{\mathrm{a}}$ & $0.17(.00)^{\mathrm{a}}$ & $b$ & $-0.02(.66)$ & & \\
\hline School attitude & $-0.10(.19)$ & $0.04(.55)$ & $-0.01(.88)$ & b & & \\
\hline Physical QoL & & & & & b & $-0.08(.13)$ \\
\hline Mental QoL & & & & & $-0.06(.33)$ & $b$ \\
\hline \multicolumn{7}{|l|}{$\begin{array}{r}\text { Effects of the mediating change factors on } \\
\text { the change in generic QoL factors }\end{array}$} \\
\hline Change in disease-specific functioning & & & & & $0.15(.01)^{\mathrm{a}}$ & $0.08(.07)$ \\
\hline Change in self-esteem & & & & & $0.25(.00)^{a}$ & $0.26(.00)^{a}$ \\
\hline Change in athletic competence & & & & & $0.05(.37)$ & $-0.02(.67)$ \\
\hline Change in school attitude & & & & & $0.14(.01)^{\mathrm{a}}$ & $0.43(.00)^{\mathrm{a}}$ \\
\hline Explained variance, $\% c$ & & & & & 44 & 59 \\
\hline \multicolumn{7}{|c|}{$\begin{array}{l}\text { All of the continuous variables are standardized to } z \text { scores (a higher score means better functioning), and all of the dichotomous variables are binary coded: ARM } 0 \text { versus HD 1, mild } 0 \text { versus severe } \\
1, \text { no additional congenital diseases } 0 \text { versus additional congenital diseases } 1 \text {, male } 0 \text { versus female 1, and no siblings } 0 \text { versus presence of siblings } 1 . \mathrm{N}=250 \text {. Overall goodness of fit: CHISQ }(20)= \\
33.46 ; P=.030 ; \text { RMSEA }=0.052 ; 90 \% \text { RMSEA confidence interval }=0.016-0.082 \text {. To save space, residual variances and covariances are not presented. } \\
\text { a Coefficients differ significantly from } 0 \text { ( } \alpha=.05 \text { ). } \\
\text { b Because of operationalization of change, effects of predictor variables at the first measurement occasion on associated change variables are } 0 \text { by definition. } \\
\text { c Our model explains } 44 \% \text { and } 59 \% \text { of the variance in change in physical and mental QoL, respectively. }\end{array}$} \\
\hline
\end{tabular}

constipation, and they all need surgical correction in early childhood. These similarities imply considerable commonality in the impact of these diseases on patients' daily functioning and QoL.

At the first measurement occasion, there were indeed no differences in disease-specific functioning, psychosocial competencies, and QoL between disease groups, indicating that patients in both patient groups seem psychologically comparable. Also, the relationships between the research variables between the 2 disease groups appeared to be equivalent. Therefore, combining ARM and HD patients in the analysis of explaining change in QoL was justified.

When comparing age groups, results showed also no differences in disease-specific functioning and QoL. However, in self-esteem and school attitude, adolescents did worse than children, but this was also true for healthy adolescents (E.E.H., F.J.O., M.A.G.S., et al, unpublished data, 2006). The lower level of self-esteem of adolescents in general (healthy and not healthy) is probably related to difficulties resulting from changes in life, such as insecurities about the developing body or problems with sexuality. The relationships between the research variables between the 2 age groups seemed to be equivalent. Therefore, we could also combine both age groups (children and adolescents) in the analysis of explaining change in QoL.

However, despite the fact that the relationships between research variables seemed to be equivalent across disease groups and age groups, children or adolescents with ARM or HD might change differently in diseasespecific functioning, psychosocial competencies, and QoL. We, therefore, included type of disease (ARM or HD) and age among the predictor variables, which only resulted in self-esteem changing differently, with ARM patients doing better.

Overall, children and adolescents with ARM or HD reported improved disease-specific functioning. Defecation problems, including symptoms (eg, fecal incontinence and constipation), as well as the emotional response to the disease (eg, feelings of shame), clearly diminish with growing age. Disease-specific improvement might be explained by more muscle control and the aid of tools, such as diapers, enemas, and dietary manipulations, and finding ways to deal with the impairments. Our results also showed improved mental QoL. Perhaps children learn to cope with their disease over the years by developing stronger psychosocial com- 
petency skills because they have to learn to live with chronic functional problems. However, this does not explain why adults reported impaired QoL in comparison to their healthy peers. ${ }^{10}$ An alternative explanation is that adolescents have a strong wish to be "normal" and, therefore, completed the QoL questionnaires as positive as possible, that is, in a socially desirable way. It might also be that parents have difficulty coping with their children's disease and accompanying impairments, which could, in turn, negatively affect the QoL of their children. The improvement in disease-specific functioning and QoL is then explained by parents who learn to deal with the illness of their child.

The results of Poley et $\mathrm{al}^{1}$ point in the same direction, although cross-sectional comparisons between different patients are not as reliable as longitudinal comparisons within the same patient group. Their results show that the youngest children ( $1-4$ years) reported the worst QoL outcomes according to their parents, although complaints of incontinence are not prominent until patients grow older; adolescents reported the best outcomes, and QoL levels of children aged 5 to 15 years varied in between. ${ }^{1}$ In this study, however, the parents were used as proxies, through which the lower level of QoL of the younger children could be explained by a disagreement between children and parent reports. A study examining parent-child agreement in assessing health status and QoL of children with inflammatory bowel disease showed that the children reported to have a better health status and QoL than their parents reported. ${ }^{23}$

A study limitation was that the response rate at the first measurement occasion was lower for ARM patients $(59 \%)$ than for HD patients $(71 \%)$, which may be because of the simultaneous study of Poley et al. ${ }^{1}$ Perhaps the overlapping inclusion of patients resulted in a loss of patients. However, our sample size is still sufficiently large. We were not able to determine to what extent selection bias may have played a role, because we were not able to assess the characteristics of the patients who did not respond to the first measurement because of confidentiality considerations. In contrast, at the second measurement occasion, the response rates between ARM and HD patients were high and comparable $(79 \%$ and $80 \%$, respectively). At the second measurement, we were able to test for differences between responding and nonresponding patients. Analysis showed that the patients who did not return the questionnaire did not differ in the clinical variables (type of disease, disease severity, additional congenital anomalies, stoma, and age at surgery). However, comparisons on the demographic variables showed that children, girls, or patients with siblings more often responded to both measurement occasions than adolescents, boys, or patients without siblings. Although almost never reaching significance, on all of the psychological variables, respondents did better than nonrespondents, perhaps indicating an over- estimation of the improvements in disease-specific functioning and QoL.

To enable tailored care for the specific needs of children and adolescents with ARM or HD, knowledge is needed about factors that affect changes in QoL. Therefore, our second question addressed the factors associated with QoL changes. Patients with HD, female patients, and those with additional congenital anomalies deteriorated in psychosocial competencies. Patients with a mild form improved in disease-specific functioning, whereas patients with a severe form did not improve. Note that the classification of disease severity is arbitrary. We choose to classify the severity of ARM or HD by the length of the affected part of the bowel, because longeraffected segments (or, with ARM, more complex forms) are usually associated with worse physical outcome or more symptoms than short (or usual) segments of the bowel. From our cross-sectional study (E.E.H., F.J.O., M.A.G.S., et al, unpublished data, 2006), it seemed that the predictor variable "disease severity" directly affected disease-specific functioning. Furthermore, the results of present study show that the severely affected patients did not improve in disease-specific functioning, whereas the less severely affected patients improved. The direct relationship between disease severity and (change in) disease-specific functioning confirmed that our classification of disease severity was justified. Patients with a severe form of the disease reported more chronic defecation problems than patients with a mild form. However, in future research, it would be nice to include more objective parameters on fecal functioning, such as anorectal manometry, or dynamic rectal imaging to enable further disentangling of the interesting relationships between objective and subjective parameters of fecal continence problems and QoL.

Children and adolescents with a higher score on athletic competencies at the first measurement occasion reported more improvement in disease-specific functioning and self-esteem over time than their less athletic peers. Thus, to reach improvement of fecal functioning and self-esteem, children and adolescents might be encouraged to engage in athletic activities. In turn, change in disease-specific functioning affected change in physical QoL. That is, patients who reported fewer physical and emotional problems with their disease over the years were, for example, less tired and had fewer problems with endurance than before.

Although some of the $\beta$ coefficients seemed to be low, the model as a whole explained $44 \%$ and $59 \%$ of the variance of change in physical QoL and mental QoL, respectively, indicating that we hypothesized correctly which predictor variables would affect changes in QoL and, thus, should be included in the study. However, this also indicates that additional but unmeasured factors play a role. Therefore, future research could include other predictors, for example, ethnicity, treatment, and 
life events, in the analyses of changes in QoL of children and adolescents with ARM or HD. Because the prevalence of ARM and HD in most ethnic groups is comparable to that in the Dutch native population, it is important to know how ethnic background may affect QoL. For example, maybe patients with different cultural backgrounds have different strategies to handle their fecal continence problems, which may affect QoL and changes in QoL. It is important to examine such cultural differences for directing further nonmedical treatment. Also, during a research period, it might be that some of the patients undergo some kind of treatment and others do not. It would be interesting to examine the possible effect of undergoing treatment on changes in diseasespecific functioning and generic QoL. Finally, when examining changes in QoL, between 2 measurements, everything can happen (eg, change of school or divorce of parents). It might be that such life events cause some changes QoL.

\section{CONCLUSIONS}

Because children and adolescents seem to do better with increasing age, both on disease-specific functioning and QoL, our results are promising for young patients with ARM or HD. Although ARM and HD are chronic diseases, with sequelae frequently continuing into adulthood, such as fecal incontinence, constipation, and sexual dysfunctioning, 4,24,25 the prospect of improvement could be hopeful for patients and for their parents. According to our results, clinicians should be specifically attentive to girls, to children and adolescents with a severe form of the disease or with additional congenital anomalies, and to those with low athletic competencies, because these are subgroups of patients who are at risk for deterioration in disease-specific functioning or psychosocial competencies and might, therefore, be in need of extra care. Furthermore, the results suggest that the QoL of children and adolescents with ARM or HD might be improved by enhancing self-esteem and promoting a more positive school attitude (achievement, behavioral conduct, and social acceptance). In general, to improve and maintain an optimal level of children and adolescents' QoL, it is important to direct treatment both to reducing symptoms and improving psychosocial competencies.

\section{ACKNOWLEDGMENTS}

This work was supported by a grant from the Netherlands Digestive Diseases Foundation and Doctors for Children.

\section{REFERENCES}

1. Poley MJ, Stolk EA, Tibboel D, Molenaar JC, Busschbach JJ. Short term and long term health related quality of life after congenital anorectal malformations and congenital diaphragmatic hernia. Arch Dis Child. 2004;89:836-841

2. Langemeijer RA, Molenaar JC. Continence After posterior sagittal anorectoplasty. J Pediatr Surg. 1991;26:587-590
3. Diseth TH, Emblem R. Somatic function, mental health, and psychosocial adjustment of adolescents with anorectal anomalies. J Pediatr Surg. 1996;31:638-643

4. Rintala R, Mildh L, Lindahl H. Fecal continence and quality of life in adult patients with an operated low anorectal malformation. J Pediatr Surg. 1992;27:902-905

5. Rintala R, Mildh L, Lindahl H. Fecal continence and quality of life for adult patients with an operated high or intermediate anorectal malformation. J Pediatr Surg. 1994;29:777-780

6. Quality of life and clinical trials. Lancet. 1995;346:1-2

7. Eiser C, Mohay H, Morse R. The measurement of quality of life in young children. Child Care Health Dev. 2000;26:401-414

8. Aaronson NK, Meyerowitz BE, Bard M, et al. Quality of life research in oncology: past achievements and future priorities. Cancer. 1991;67:339-343

9. World Health Organization. Preamble to the Constitution of the World Health Organization as adopted by the International Health Conference, New York, June 19-22, 1946; signed on July 22, 1946, by the representatives of 61 states (official records of the World Health Organization, No. 2, p 100) and entered into force on April 7, 1948. Geneva, Switzerland: World Health Organization; 1947

10. Hartman EE, Oort FJ, Aronson DC, et al. Critical factors affecting quality of life of adult patients with anorectal malformations or Hirschsprung's disease. Am J Gastroenterol. 2004;99: 907-913

11. Wilson IB, Cleary PD. Linking clinical variables with healthrelated quality of life: a conceptual model of patient outcomes. JAMA. 1995;273:59-65

12. Guyatt GH, Feeny DH, Patrick DL. Measuring health-related quality-of-life. Ann Intern Med. 1993;1 18:622-629

13. Vogels T, Verrips GH, Koopman HM, Theunissen NC, Fekkes M, Kamphuis RP. TACQoL Manual Parent and Child Form. Leiden, Netherlands: Leiden Center for Child Health and Paediatrics LUMC-TNO; 2000

14. Vogels T, Bruil J, Koopman HM, Fekkes M, Verrips GH. TACQoL CF 12-15 Manual Child Form. Leiden, Netherlands: Leiden Center for Child Health and Paediatrics LUMC-TNO; 2004

15. Hanneman MJ, Sprangers MA, De Mik EL, et al. Quality of life in patients with anorectal malformations or hirschsprung's disease: the development of a disease-specific questionnaire. Dis Colon Rectum. 2001;44:1650-1660

16. Harter S. Manual for the Self-perception Profile for Children. Denver, CO: University of Denver; 1985

17. Harter S. Manual for the Self-perception Profile of Adolescents. Denver, CO: University of Denver; 1986

18. Hassink EA, Rieu PN, Hamel BC, Severijnen RS, vd Staak FH, Festen C. Additional congenital defects in anorectal malformations. Eur J Pediatr. 1996;155:477-482

19. Cohen J. Statistical Power Analysis for the Behavioral Sciences. Hillsdale, NJ: Lawrence Erlbaum Associates; 1988

20. Bollen KA. Structural Equations With Latent Variables. New York, NY: Wiley; 1989

21. Browne MW, Cudeck R. Alternative ways of assessing model fit. Sociol Method Res. 1992;21:230-258

22. Joreskog KG, Sorbom D. LISREL 8 User's Guide. Chicago, IL: Scientific Software International, Inc; 1996

23. Loonen HJ, Koopman HM, Derkx BHF, Heymans HSA. Are parents able to rate the symptoms and quality of life of their offspring with IBD? Inflamm Bowel Dis. 2002;8:270-276

24. Diseth TH, Egeland T, Emblem R. Effects of anal invasive treatment and incontinence on mental health and psychosocial functioning of adolescents with Hirschsprung's disease and low anorectal anomalies. J Pediatr Surg. 1998;33:468-475

25. Kamm MA. Fortnightly review: faecal incontinence. BMJ. 2002;316:528-532 


\section{Explaining Change in Quality of Life of Children and Adolescents With Anorectal Malformations or Hirschsprung Disease}

Esther E. Hartman, Frans J. Oort, Daniel C. Aronson, Marianne J.G. Hanneman,

Ernest van Heurn, Zacharias J. de Langen, Gerard C. Madern, Paul N.M.A. Rieu, David C. van der Zee, Nic Looyaard, Marina van Silfhout-Bezemer and Mirjam A.G. Sprangers

Pediatrics 2007;119; e374

DOI: $10.1542 /$ peds. 2006-0212

\section{Updated Information \& Services}

References

Citations

Subspecialty Collections

Permissions \& Licensing

Reprints including high resolution figures, can be found at: http://pediatrics.aappublications.org/content/119/2/e374.full.h tml

This article cites 17 articles, 2 of which can be accessed free at:

http://pediatrics.aappublications.org/content/119/2/e374.full.h tml\#ref-list-1

This article has been cited by 3 HighWire-hosted articles: http://pediatrics.aappublications.org/content/119/2/e374.full.h tml\#related-urls

This article, along with others on similar topics, appears in the following collection(s):

Gastrointestinal Tract

http://pediatrics.aappublications.org/cgi/collection/gastrointes tinal_tract

Information about reproducing this article in parts (figures, tables) or in its entirety can be found online at: http://pediatrics.aappublications.org/site/misc/Permissions.xht $\mathrm{ml}$

Information about ordering reprints can be found online: http://pediatrics.aappublications.org/site/misc/reprints.xhtml

PEDIATRICS is the official journal of the American Academy of Pediatrics. A monthly publication, it has been published continuously since 1948. PEDIATRICS is owned, published, and trademarked by the American Academy of Pediatrics, 141 Northwest Point Boulevard, Elk Grove Village, Illinois, 60007. Copyright @ 2007 by the American Academy of Pediatrics. All rights reserved. Print ISSN: 0031-4005. Online ISSN: 1098-4275.

\section{American Academy of Pediatrics}

